\title{
Impact of Team Climate on Co-Creativity in STEAM Education in Primary Education
}

\author{
Charlotte Stinkeste ${ }^{1}$, Axelle Napala ${ }^{2}$, Margarida Romero² \\ ${ }^{1}$ Université de Lille, Lille, France \\ ${ }^{2}$ Université Côte D’Azur, Nice, France \\ Email: charlotte.stinkeste.etu@univ-lille.fr, axelle.napala@etu.univ-cotedazur.fr, margarida.romero@unice.fr
}

How to cite this paper: Stinkeste, C., Napala, A., \& Romero, M. (2021). Impact of Team Climate on Co-Creativity in STEAM Education in Primary Education. Creative Education, 12, 1977-1994. https://doi.org/10.4236/ce.2021.128151

Received: July 15, 2021

Accepted: August 27, 2021

Published: August 30, 2021

Copyright (c) 2021 by author(s) and Scientific Research Publishing Inc. This work is licensed under the Creative Commons Attribution International License (CC BY 4.0).

http://creativecommons.org/licenses/by/4.0/

(c) (i) Open Access

\begin{abstract}
The need to introduce co-creative approaches in education is nowadays seen as a way to support STEAM education. However, in collaborative activities, the team climate in which learners work seems to have an impact on them. In this context, this study sought to prove that team climate has an impact on the co-creativity of primary school students. Specifically, after completing a co-creative challenge, we administered the CoCreat questionnaire to 109 children, investigating three factors: the team climate in which the children operate, their co-creativity and, the process by which they complete the challenge. The results of the questionnaire showed that when children felt confident and could express their feelings freely within their team (i.e. a good team climate), this increased their scores for the last two factors. On the contrary, when children indicated that they were in an atmosphere of low trust, without conflict management, for example (i.e. a bad team climate), their scores on these two factors were greatly reduced. These results show that it is not enough to use co-creativity tools to develop co-creativity; one must be able to use them in a positive climate.
\end{abstract}

\section{Keywords}

Co-Creativity, STEAM Education, Team Climate, Primary School, Techno-Creative Activities

\section{Introduction}

\subsection{From Individual Creativity to Co-Creativity}

When creativity is discussed, there is often reference to individual work related to the arts, often in relation to different traits of personality (Brown, 1989; Guilford, 1950; Fleming, 2010). Even in educational contexts, creativity has been as- 
sessed mainly by focusing on individual activities (Jones, 2009; Katz-Buonincontro \& Anderson, 2018). However, the definition of creativity is not restrictive regarding the context of expression. It is simply described as an ability to make a production that is new, original, and contextually appropriate (Lubart, Mouchiroud, Tordjman, \& Zenasni, 2015). Wishart and Eagle (2014) argue that mere creativity is no longer enough in today's world, as important creations are nowadays, almost always the result of complex collaborations. For them, it becomes necessary to include co-creativity (i.e., creative collaboration). This idea is shared by Lambropoulos et al. (2011) and by Romero and Barberà (2014) in educational contexts, or by Harper et al. (2008) who suggest that co-creativity is something that turns us into essentially human beings and that it is necessary to continue to appear with technology.

Thus, in this context, this study will focus on the process of co-creativity, which will be considered here as a collaborative process in which learners engage in the development of a creative solution.

\subsection{Studying Co-Creativity in STEAM Education}

Recently, some studies have recognized the need to introduce creative (Puozzo, 2016; Bolden, DeLuca, Kukkonen, Roy, \& Wearing, 2020) and co-creative approaches (Heiser, Romero, De Smet, \& Faller, 2020; Romero, Lille and Patino, 2017; Voogt et al., 2015) in education. Indeed, as individuals have to adapt more and more quickly to societal or economic changes (Sternberg, 2015), each person needs to be able to create new solutions to cope with changes in order to bring innovations and also to stay competitive (van Laar, van Deursen, van Dijk, \& de Haan, 2017). Thus, it becomes necessary to focus on the development of these skills starting in primary education (Ferrari, Cachia, \& Punie, 2009). To do so, one approach that has gained more and more popularity is STEAM education, also known as Science, Technology, Engineering, Arts and Mathematics. It is a pedagogy that merges the arts with STEM subjects (Science, Technology, Engineering and Mathematics), for the purpose of emphasizing the significance of integrating domain general skills such as perspective-taking, creative and problem-solving skills, knowledge transfer across disciples, and/or encouraging students to explore and experience new ways of knowing (Perignat \& KatzBounincontro, 2019). STEAM education therefore provides an opportunity to harness co-creativity in schools, and we have used this pedagogy to study it.

\subsection{Techno-Creative Activities as a Means to Generate Co-Creativity}

According to a study by Oner et al. (2016), students should have the opportunity in the formal school setting to use both creativity and logical thinking processes to solve problems. The Maker movement, defined by Anderson (2012) as "those who make", where almost anyone can make almost anything, is a good example. This "playful" or "game-based" approach has been described as fostering creativity (Davies et al., 2013). However, only one study has so far documented 
learners' co-creativity when engaging in Making projects (Timotheou \& Ioannou, 2021). In their study, the authors adopted a Making approach in STEAM domains, to examine student's co-creativity when engaging in making projects, using artistic, craft and technological tools (also called techno-creative tools). The results showed that these activities promoted the development of co-creativity and that there was a statistically significant linear relationship between co-creativity and project success. Therefore, it can be stated that techno-creative activities, which engage participants in a challenge to be solved creatively through the use of digital or analog technologies (Romero, Lille, \& Patiño, 2017), are educational activities supporting co-creativity and their assessment. In light of this, and in order to further document what we know about learners' co-creativity when engaging in making projects, this study used the techno-creative activities created by the company Trezorium to investigate the co-creativity of young students. Trezorium has created an online database called Makerium.fr, which allows teachers to find creative and cross-curricular challenges for young makers. The advantage of this approach is that it presents a techno-creative activity as a challenge. This allows children to feel that they are developing new skills, which increases their motivation to carry out the activity (Csikszentmihalyi, 1998).

\subsection{Assessment of Co-Creativity}

To measure children's co-creativity after they have completed the activity, it was necessary to find a suitable tool. Recently, David and collaborators (submitted) developed a co-creativity scale called CoCreat, based on the literature review of the different components of creativity performed in collaborative learning contexts. The CoCreat scale was intended to be an instrument to analyze the creativity process in a collaborative learning context in secondary and post-secondary education. It assesses three main factors (Figure 1): Team Climate, Co-Creative Process and Solution Orientation. The Team Climate factor collects information about how the team is able to create a good atmosphere of trust that encourages each member to freely share different points of view on a subject (Trust Climate). It further tackles the expression of positive and negative emotions (Expression of Emotions) and the manner of overcoming different challenges and resolving various conflicts that existed during the process (Conflict Management) while still being able to have informal yet productive discussions (Informal Discussions). The second factor, called Co-Creative Process, gathers data on how participants worked together towards the same objective (Coordination). In addition, it also talks about how the team was able to openly share various ideas (Idea Sharing) and adapt them according to the challenges faced (Difficulties Adaptation) in the different stages of the process before finalizing an end-product (Iterative Process). Finally, the Solution Orientation factor collects information on how the team was able to successfully develop new, original and effective solutions that have value and that respond to the constraints of the situation (New and Original Solutions, Value of the Solution \& Efficiency of the Solution). 


\begin{tabular}{|c|c|c|}
\hline \multirow{4}{*}{ Team Climate } & Trust Climate & $\begin{array}{l}\text { "We worked in an atmosphere of trust } \\
\text { facilitating the expression of different points } \\
\text { of view" }\end{array}$ \\
\hline & Expression of Emotions & $\begin{array}{l}\text { "We were able to express our emotions, both } \\
\text { positive and negative" }\end{array}$ \\
\hline & Informal Discussions & "We had informal discussions" \\
\hline & Conflict Management & $\begin{array}{l}\text { "We have been able to overcome conflicts in a } \\
\text { positive way" }\end{array}$ \\
\hline \multirow{4}{*}{ Co-Creative Process } & Sharing of Ideas & "We shared different ideas" \\
\hline & Iterative Process & "We have developed intermediate versions" \\
\hline & Difficulties Adaptation & $\begin{array}{l}\text { "We were able to adapt ideas and practices } \\
\text { throughout the project according to the } \\
\text { difficulties" }\end{array}$ \\
\hline & Coordination & "We coordinated well" \\
\hline \multirow{5}{*}{ Solution Orientation } & Efficient Collaboration & $\begin{array}{l}\text { "We have succeeded in developing an } \\
\text { efficient collaboration" }\end{array}$ \\
\hline & Co-construction of Solution & $\begin{array}{l}\text { "We have succeeded in developing an } \\
\text { efficient solution" }\end{array}$ \\
\hline & New and Original Solutions & $\begin{array}{l}\text { "We have succeeded in developing a new and } \\
\text { original solution" }\end{array}$ \\
\hline & Value of the Solution & $\begin{array}{l}\text { "We have succeeded in developing a solution } \\
\text { that has value and meets the constraints of the } \\
\text { situation" }\end{array}$ \\
\hline & Efficiency of Solution & $\begin{array}{l}\text { "We have succeeded in developing an } \\
\text { efficient solution, which uses a number of } \\
\text { limited resources" }\end{array}$ \\
\hline
\end{tabular}

Figure 1. Factors of the CoCreat Scale and its items.

Moreover, it also talks about the teamwork of the group in the process of achieving a common goal or to find a solution in the most effective and efficient way (Efficient Collaboration \& Co-Construction of Solution).

The advantage of the CoCreat scale is that it not only allows for the study of participants' co-creativity during the activity, but also places the activity in a context, which is itself evaluated. As the primary location of students' learning activities, schools are important environments that affect students' physical and mental development (Eccles \& Roeser, 2011). Following on from this line of reasoning, it is possible to assume that in collaborative activities, the climate in which students operate could also have an impact on students.

\subsection{The Importance of Team Climate}

In 2008, Eteläpelto and Lahti published an article after studying co-creativity in student groups. The results showed that the main obstacles to creative collaboration were related to the emotional atmosphere and power relations of the group. They found that a group where participants invalidated opposing views was rated as less creative, and that the group atmosphere was emotionally charged in a negative sense. Similarly, a group atmosphere that was rated as unsafe caused group members to fear being emotionally hurt by other members. In contrast, the most creative situation was characterized by the complementary nature of the participants' words and the inclusive use of others' views.

\subsection{Aims and Hypothesis}

In view of the above, we wondered about the relationship between the team climate and the co-creativity of primary school pupils, as revealed by the CoCreat 
scale. Following this reflection, we have also sought to identify the relationships between team climate and the solution orientation process carried out by the groups. More specifically, we assume that the positive or negative feeling of the students within their team will have an impact on their perception of the solution orientation and the co-creativity process they perform. As a result, we assume that a team with a good team climate will have a positive impact on the solution orientation process of the group rather than one with a bad team climate. Similarly, we assume that a team with a good team climate will have a positive impact on the group's co-creative process rather than one with a bad team climate.

\section{Method}

\subsection{Participants}

In order to carry out this study and to evaluate creativity in STEAM education, 8 public primary schools have been mobilized. They were selected in the district of Béthune (Pas-de-Calais), located in the north of France. In these schools, 10 teachers agreed to participate in the study. Their classes range from CP to CM2, and 109 children (59 boys and 45 girls) aged 7 to 11 have answered the questionnaire. In order to participate in this experiment, each child had to obtain written consent from their parents. The consent form explained the purpose of the study and the parents were told that they were free to withdraw their consent at any time. On each consent, a unique ID was present to make the data anonymous. It was given randomly between classes and between students. There were no exclusion criteria, and no compensation was provided. Before starting the questionnaire, the teachers and students were told the purpose of the study and the voluntary nature of their participation. The study was approved by the university's research ethics committee and by the school's referral inspector.

\subsection{Material}

\subsubsection{Questionnaire}

In order to assess co-creativity in primary schools, a simplified version of the CoCreat questionnaire was created. As it was necessary to reduce the size of the questionnaire before giving it to the children, only three sub-criteria were retained per factor. They were considered as the basis of the statements in the new version of the questionnaire (Figure 2). The team climate factor tackles the level of trust each participant has in other group members (Trust climate), how they resolve certain conflicts within their group (Conflict management), and how well they have coordinated to achieve the same goal (Coordination). The co-creative process factor, talks about how each member of the group successfully and freely shares their ideas with their team (Sharing ideas), how they have adapted to certain changes during the different phases of the activity (Difficulties adaptation) and the different cycles of calculated trial and error that they had to go through before arriving at the desired end result (Iterative process). Finally, the third 


\begin{tabular}{|c|c|c|}
\hline \multirow{3}{*}{$\begin{array}{c}\text { Team } \\
\text { Climate }\end{array}$} & Trust climate & Q1. We were able to build trust with the other team members and share different points of view \\
\hline & $\begin{array}{c}\text { Conflict } \\
\text { management }\end{array}$ & Q2. We managed to work together even if we didn't agree, without arguing \\
\hline & Coordination & Q3. We were able to organise our work well within our team. \\
\hline \multirow{3}{*}{$\begin{array}{c}\text { Cocreative } \\
\text { process }\end{array}$} & Sharing ideas & Q4. Different team members were able to share different ideas. \\
\hline & Iterative process & Q5. We developed intermediate versions before arriving at the final solution. \\
\hline & $\begin{array}{l}\text { Difficulties } \\
\text { adaptation }\end{array}$ & Q6. When we encountered difficulties, we adapted our ideas and the way we did the activity. \\
\hline \multirow{3}{*}{$\begin{array}{c}\text { Solution } \\
\text { orientation }\end{array}$} & $\begin{array}{l}\text { Value of the } \\
\text { solution }\end{array}$ & Q7. We managed to create a good solution, which respected the instructions. \\
\hline & $\begin{array}{c}\begin{array}{c}\text { Efficiency of the } \\
\text { solution }\end{array} \\
\end{array}$ & Q8. We managed to develop a solution that uses just the right resources. \\
\hline & $\begin{array}{c}\text { Original and new } \\
\text { solution }\end{array}$ & Q9. We managed to develop a good, new and original solution. \\
\hline
\end{tabular}

Figure 2. Factors of the simplified CoCreat Scale and its items.

factor, solution orientation, discusses the effective, new and original solution (Original and new solution) with value that participants found during the activity (Value of the solution). It also measures how efficiently they were able to use the resources provided to them (Efficiency of the solution). The original questionnaire has been reduced to two pages: the first page gathers information such as the school participants come from, the number of people in their team, the solution their group found during the activity, their gender and their birth year. The second page contains nine statements (Figure 2) in which they had to respond according to their degree of agreement. Five response options were available for each question: "Strongly disagree", "Rather disagree", "Neither agree nor disagree", "Rather agree" and "Strongly agree".

As not all schools had computers, a paper version of the simplified questionnaire was given to each student. Its online version was also created on a site called LimeSurvey for data processing purposes. The latter, however, was only used by the experimenters.

\subsubsection{Techno-Creative Activity}

The chosen techno-creative activity is available on the Makerium.fr platform and is feasible for all classes. Due to the lack of equipment in some schools, the activity did not require too much digital equipment. Therefore, the Trézorium team suggested the "Pixel Art" challenge to the teachers, and they all accepted to carry it out.

Pixel art is a kind of digital art where images are created and edited at the pixel level. It was made popular around the 1970s when computers and digital art began to gain relevance. What defines pixel art is its unique visual style, where each pixel functions as the founding elements of a complete image. The effect of this type of art is a visual style very similar to that of mosaic art, beadwork, cross stitch and other types of embroidery techniques.

This challenge was composed of three sessions: 1 ) a session on the history of Pixel Art and explaining the context, 2) a session of individual work allowing the children to discover pixel art thanks to different supports like computers, stickers, ironing beads or paper and pencil (Figure 3), and finally 3) a collective 


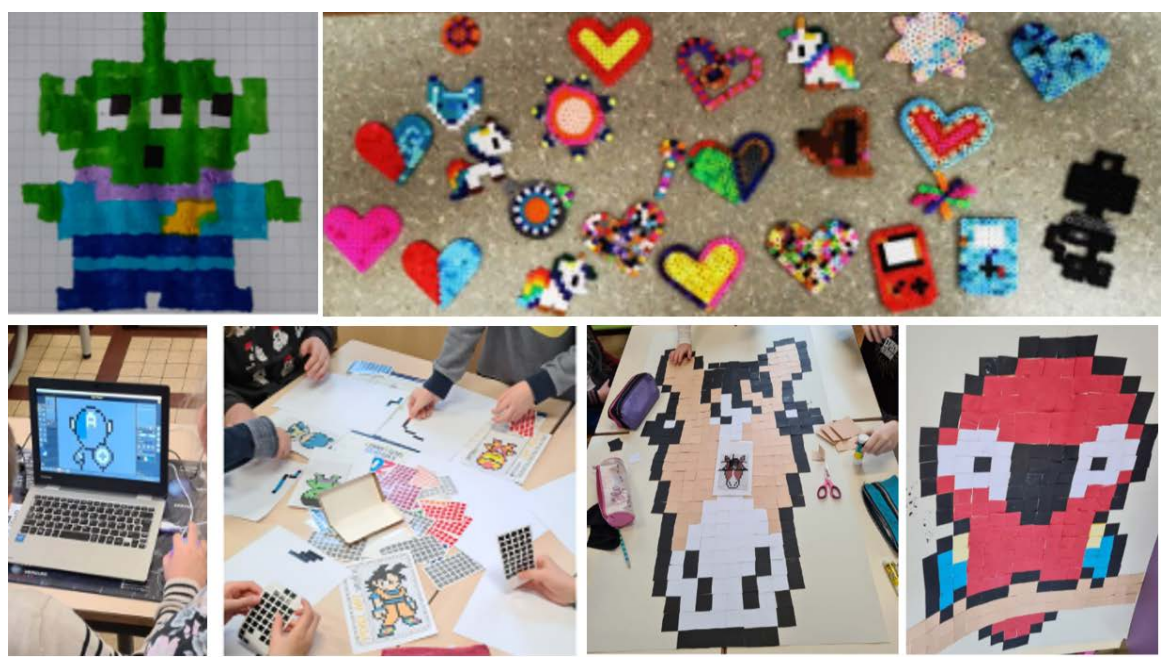

Figure 3. Realization of the Pixel Art challenge: with felt pens, ironing beads, a computer, gomettes and post-its.

challenge session. During this last session, the children were asked to create, in groups of at least two people, a giant Pixel Art made of post-its. It was on this part that the co-creativity of the children was evaluated.

The challenge allows children to work on a wide range of skills that are part of the French "Socle commun de connaissances, de compétences et de culture". For example, in the visual arts, it teaches them to experiment, produce, create, implement an art project, express themselves, analyses their practice and that of their peers and be sensitive to art issues. The challenge also allows them to question the world by appropriating tools and methods, by mobilising digital tools and by placing themselves in space and time. Finally, this challenge also provides children with mathematical skills such as research and modelling.

\subsection{Experimental Procedure}

Before carrying out the Pixel Art challenge, a collective meeting was organised online with the teachers, the members of Trézorium, as well as the researchers involved in the project, in order to present the platform Makerium, the study, as well as the definition of creativity. Following this, the Trézorium team suggested the "Pixel Art" challenge to the teachers. Then, one of the experimenters contacted the teachers to determine how much time they felt was needed to complete the challenge. Although the Makerium.fr platform recommends three sessions, the teachers all took it upon themselves to adapt it to their class and their students. Then, they arrange a date with them to carry out the challenge in class.

Subsequently, the teachers carried out sessions (1) and (2) if they wished. An experimenter was present in four of the classes for the second session at the request of the teachers, in order to observe and help if necessary. Bearing in mind that this study aims to assess co-creativity, the collective challenge session (3) was mandatory and was carried out by all the classes. Although the teachers were allowed to organize the challenge in their own way, the instructions were the 
same for each class: they had to do the activity in teams of two or more students $(\mathrm{m}=3.67$; $\mathrm{sd}=0.99)$. The Pixel Art challenge lasted between two hours or more.

Once the group challenges were over, the children had to complete the simplified version of the CoCreat questionnaire. As it was the first time that the teachers administered this questionnaire in class, an experimenter was present to verify that they all followed the same methodology and that the children had the same explanations. Therefore, the teacher or the experimenter read the questions aloud, and the students were asked to answer the questions one after the other. It was made clear to them beforehand that they were free to ask questions if they had any problems (especially about the meaning of words), that the questionnaire was completely anonymous and that there were no right or wrong answers. For future challenges, the teachers will be the only ones to administer the questionnaire.

\subsection{Data Analysis}

As the participants answered the questions on paper, the data had to be computerized. The experimenters scanned the questionnaires and uploaded their responses one by one to the LimeSurvey online questionnaire. After scanning was completed, the data had to be transformed. Thus, the responses on the scale ranging from "Strongly disagree" to "Strongly agree" were transformed into numerical data ranging from 0 to 4 (see Table 1). Participants with missing or inconsistent data were then removed.

The aim of this study was to know if team climate could play an important role in promoting the co-creative process and in finding effective solutions to a problem. In order to determine which participants belong to a team with a good or bad team climate, the mean was used. Subsequently, assumption checks such as Shapiro-Wilk's Test of Normality and Lavene's test of Equality of Variances were performed with the aim of choosing the appropriate tests (parametric or nonparametric) to conduct in the analysis of the dataset acquired using the simplified CoCreate questionnaire.

\section{Results}

\subsection{Description of the Data}

The qualitative data (scale from "strongly disagree" to "strongly agree") were transformed into quantitative data (from 0 to 4), for each of the 9 questions and for each of the 109 participants. They were then summed for each factor (e.g. for the team climate factor, we summed the scores of questions 1 to 3 ). The mean

Table 1. Descriptive statistics of the dataset.

\begin{tabular}{cccc}
\hline & Team Climate & Co-Creative Process & Solution Orientation \\
\hline Mean & 2.807 & 2.440 & 3.061 \\
Std. Deviation & 1.212 & 0.862 & 0.805 \\
\hline
\end{tabular}


scores for each factors were then calculated (see Table 1). Based on the results, it is evident that there is a more variation or dispersion of a set of values for Team Climate compared to the other two factors; its values are spread out over a wider range.

\subsection{Analysis per Question}

During the initial analysis, charts of the results of each of the statements in the simplified questionnaire were produced to visualize the answers given by the participants. They have been classified according to the factor to which they belong. Table 2 shows the results of the responses to statements that fall under the team climate factor. More than $40 \%$ of the participants answered "Strongly Agree" to questions one (Q1) to three (Q3), suggesting that a lot of them coordinated well with their respective groups during the activity.

Table 3 shows the result of the responses to the Co-Creative Process factor. More than $40 \%$ of the participants answered "Strongly agree" to statements four (Q4) and six (Q6) meaning that there was a sharing of ideas within the teams and that most of them felt they were able to adapt to the difficulties. For statement five (Q5), however, most participants responded "Strongly Disagree" indicating that they had not gone through an iterative process before arriving at a final solution.

Table 2. Responses to statements of the team climate factor.

\begin{tabular}{cccc}
\hline & $\begin{array}{c}\text { Trust Climate } \\
(\mathrm{Q} 1)\end{array}$ & $\begin{array}{c}\text { Conflict } \\
\text { Management (Q2) }\end{array}$ & $\begin{array}{c}\text { Coordination } \\
\text { (Q3) }\end{array}$ \\
\hline Mean & 2.743 & 2.743 & 2.936 \\
Std. Deviation & 1.212 & 0.862 & 0.805 \\
\% of "Strongly Disagree" responses & 12.844 & 11.927 & 11.009 \\
\% of "Rather Disagree" responses & 9.1743 & 11.927 & 5.505 \\
\% of "Neither Agree nor disagree" responses & 9.174 & 8.257 & 12.844 \\
\% of "Rather Agree" responses & 28.440 & 25.688 & 20.183 \\
\% of "Strongly Agree" responses & 40.366 & 42.202 & 50.459 \\
\hline
\end{tabular}

Table 3. Responses to statements of the co-creative process factor.

\begin{tabular}{cccc}
\hline & $\begin{array}{c}\text { Sharing Ideas } \\
(\mathrm{Q} 4)\end{array}$ & $\begin{array}{c}\text { Iterative Process } \\
(\mathrm{Q} 5)\end{array}$ & $\begin{array}{c}\text { Difficulties } \\
\text { Adaptation (Q6) }\end{array}$ \\
Mean & 2.853 & 1.817 & 2.651 \\
Std. Deviation & 1.366 & 1.684 & 1.436 \\
\% of "Strongly Disagree" responses & 11.927 & 40.3670 & 13.761 \\
\% of "Rather Disagree" responses & 7.339 & 5.505 & 9.174 \\
\% of "Neither Agree nor disagree" responses & 7.339 & 11.009 & 15.596 \\
\% of "Rather Agree" responses & 30.275 & 18.349 & 21.101 \\
\% of "Strongly Agree" responses & 43.119 & 24.771 & 40.367 \\
\hline
\end{tabular}


Finally, concerning the third factor, Solution Orientation (Table 4), the majority of participants (more or less 60\%) responded "Strongly Agree" to statements seven (Q7) and nine (Q9) showing that their groups were able to develop good solutions that were new, original and in accordance with the instructions. In addition, most participants responded either "Rather Agree" or "Strongly Agree" to statement eight (Q8) about how they managed to develop a solution that only used the necessary resources.

\subsection{Identifying the BadTeamClimate and GoodTeamClimate Groups}

The mean of the team climate factor is 2.807. As mentioned previously, it was used to group participants of the study. If a participant has scored over 2.807 in Team Climate, he/she belonged to a team with a good team climate, if otherwise, he/she belonged to a team with a bad team climate. It was determined that 44 participants, whose scores ranged from 0 to 2.67, are in groups with a bad team climate and 65, whose scores are from 3 to 4 , were members of groups with a good team climate.

\subsection{Assumption Checks}

Preliminary data screening on the Co-Creative Process variable showed that the score of the group BadTeamClimate $(p=0.116)$ has met the assumptions of normality with a Shapiro-Wilk's test (Table 5). On the other hand, the group GoodTeamClimate came out to be significant with a p-value of 0.011 suggesting

Table 4. Responses to statements of the solution orientation factor.

\begin{tabular}{cccc}
\hline & $\begin{array}{c}\text { Value of the } \\
\text { Solution (Q7) }\end{array}$ & $\begin{array}{c}\text { Efficiency of the } \\
\text { Solution (Q8) }\end{array}$ & $\begin{array}{c}\text { Original and } \\
\text { New Solution (Q9) }\end{array}$ \\
Mean & 3.468 & 2.541 & 3.174 \\
Std. Deviation & 0.987 & 1.358 & 1.246 \\
\% of "Strongly Disagree" responses & 4.587 & 14.679 & 6.422 \\
\% of "Rather Disagree" responses & 0 & 7.339 & 8.257 \\
\% of "Neither Agree nor disagree" responses & 8.257 & 14.679 & 6.422 \\
\% of "Rather Agree" responses & 18.349 & 35.780 & 19.266 \\
\% of "Strongly Agree" responses & 68.807 & 27.523 & 59.633 \\
\hline
\end{tabular}

Table 5. Test of normality (Shapiro-Wilk).

\begin{tabular}{lccc}
\hline & & $\mathrm{W}$ & $p$ \\
\hline \multirow{2}{*}{ Co-Creative Process } & BadTeamClimate & 0.959 & 0.116 \\
& GoodTeamClimate & 0.950 & 0.011 \\
& BadTeamClimate & 0.897 & $<0.001^{*}$ \\
Solution Orientation & GoodTeamClimate & 0.891 & $<0.001^{*}$
\end{tabular}

*Significant results suggest a deviation from normality. 
a deviation from normality. The scores of both groups, BadTeamClimate and GoodTeamClimate, of the Solution Orientation variable did not meet the assumptions of normality resulting in the same $p$-values of $<0.001$.

The Levene's test of Equality of Variances (Table 6) was not significant for the Co-creation process variable. It had a $p$-value of 0.776 indicating that the assumption of homogeneity of variance had been met. The Solution Orientation variable, however, was significant $(p=0.002)$ suggesting a violation of the equality of variance assumption.

\subsection{Impact of Team Climate on the Other Factors}

Due to the results of the assumption checks on normality and equality of variances, parametric and nonparametric tests were used to determine whether team climate has an impact on the co-creative process and on the search for effective solutions to problems.

An independent samples t-test, an example of a parametric test, was carried out to compare the groups on the Co-Creative Process variable. The aforementioned hypothesis states that participants belonging to a group with a good team climate will more likely promote the process of co-creativity than those belonging to a group with a bad team climate. Since it has been defined that one group is better than the other, the test was one-tailed or directional.

Table 7 shows that the groups differ significantly $(p \leq 0.001)$.

Unlike the Co-Creative Process variable, an alternative nonparametric test, the Mann-Whitney U test (Table 8), was used to compare groups on the Solution Orientation variable, as it was found to be significant in the assumption checks (Shapiro Wilk's Test of Normality and Lavene's Test on Equal Gaps)

Table 6. Test of equality of variances (Levene's).

\begin{tabular}{cccc}
\hline & F & df & $p$ \\
\hline Co-Creative Process & 0.081 & 1 & 0.776 \\
Solution Orientation & 9.972 & 1 & $0.002^{*}$
\end{tabular}

*Significant results suggest a violation of the equality of variance assumption.

Table 7. Independent samples t-test.

\begin{tabular}{cccc}
\hline & $\mathrm{t}$ & $\mathrm{df}$ & $p$ \\
\hline Co-Creative Process & -3.414 & 107 & $<0.001^{*}$ \\
\hline
\end{tabular}

The alternative hypothesis specifies that group BadTeamClimate is less than group GoodTeamClimate. *Significant results suggest that the groups differ significantly.

Table 8. Mann-Whitney U test.

\begin{tabular}{cccc}
\hline & W & df & $p$ \\
\hline Solution Orientation & 725 & 107 & $<0.001^{*}$ \\
\hline
\end{tabular}

The alternative hypothesis specifies that group BadTeamClimate is less than group GoodTeamClimate. ${ }^{*}$ Significant results suggest that the groups differ significantly. 
conducted previously. The hypothesis states that participants who belonged to a group with a good team climate are more likely able to create effective, new and original solutions to problems than those who belonged to a group with a bad team climate. The test was also one-tailed or directional. The test revealed significant differences between the two groups $(p \leq 0.001)$.

\subsection{Additional Analysis}

Following the analysis of the team climate, it was decided that a further analysis should be carried out. In the previous test conducted, it was determined that team climate is affected by the group members that compose it. It was therefore necessary to know whether the choice of partners had an impact on the results. During the conduct of the techno-creative activity in class, the teachers were asked if they had let the children choose their group or if the groups had been imposed. The same tests were then carried out with two new groups: "Imposed" and "Not-imposed".

\subsubsection{Assumption Check}

When examining the data on the Team Climate variable, the results for the Imposed and Non-imposed groups were found to be significant with $p$-values of $<0.001$ using a Shapiro-Wilk test (Table 9). Similar results were also shown in the Solution Orientation variable with a $p$-value of 0.001 for the Imposed group and $<0.001$ for the Non-imposed group. Both results indicate that the normality assumptions had not been met. The results for the Co-Creative Process variable are however slightly different from the other factors; it showed a $p$-value of 0.030 for the Imposed group and 0.057 for the Non-imposed group.

The Levene's test of Equality of Variances (Table 10) showed non-significant

Table 9. Test of normality (Shapiro-Wilk).

\begin{tabular}{cccc}
\hline & & $\mathrm{W}$ & $p$ \\
\hline Team Climate & Imposed & 0.877 & $<0.001^{*}$ \\
Co-Creative Process & NonImposed & 0.844 & $<0.001^{\star}$ \\
& Imposed & 0.937 & 0.030 \\
Solution Orientation & Imposed & 0.966 & 0.057 \\
& NonImposed & 0.890 & $0.001^{*}$ \\
& Non Imposed & 0.872 & $<0.0001^{\star}$ \\
\hline
\end{tabular}

*Significant results suggest that the groups differ significantly.

Table 10. Test of equality of variances (Levene's).

\begin{tabular}{cccc}
\hline & $\mathrm{F}$ & $\mathrm{df}$ & $p$ \\
\hline Team Climate & 2.915 & 1 & 0.091 \\
Co-Creative Process & $6.473 \mathrm{e}-5$ & 1 & 0.994 \\
Solution Orientation & 0.585 & 1 & 0.446 \\
\hline
\end{tabular}


results for all variables: Team Climate, Co-Creative Process and Solution Orientation. It had $p$-values of $0.091,0.994$ and 0.446 respectively. The assumption of homogeneity of variance had been met.

\subsubsection{Impact of Groups Imposed and Non-Imposed on Team Climate, Co-Creative Process and Solution Orientation}

The results of the assumption checks on normality and equality of variances suggest that parametric and nonparametric tests should again be used. This is to determine whether the two groups, Imposed and Non-imposed, can have impacts on the three variables previously mentioned.

An alternative nonparametric test, Mann Whitney (Table 11), was carried out to compare the groups Imposed and Non-imposed to the Team Climate and Solution Orientation variables. The test was two-tailed or non-directional.

A significant result was shown for the Team Climate variable with a $p$-value of 0.011 . On the contrary, the result of the Solution Orientation variable was found to be non-significant $(p=0.411)$.

Since the Co-Creative Process variable has met both assumption checks on normality and equality of variances, a parametric test (Independent Samples T-Test) was used. The test was also two-tailed or non-directional. It revealed nonsignificant results with a $p$-value of 0.058 (Table 12).

\section{Discussion}

This study focuses on the impact of team climate on co-creativity and the process of finding solutions to a techno-creative challenge created on the Makerium.fr platform for elementary school students. It also discusses the assessment of co-creativity which was carried out by means of a questionnaire composed of three main factors (team climate, co-creative process and solution orientation) and of three items under each one. Initially, we assumed that the positive or negative feeling of the students within their team would have an impact on the co-creative process of the participants and on their perception of the solution orientation. The hypotheses suggested that a good team climate would lead to stronger results in both Co-Creative Process and Solution Orientation factors

Table 11. Mann-Whitney U test.

\begin{tabular}{cccc}
\hline & $\mathrm{W}$ & $\mathrm{df}$ & $p$ \\
\hline Team Climate & 967.000 & 107 & $0.011^{\star}$ \\
Solution Orientation & 1236.000 & 107 & 0.411
\end{tabular}

The alternative hypothesis specifies that group BadTeamClimate is less than group GoodTeamClimate. *Significant results suggest that the groups differ significantly.

Table 12. Independent samples T-test.

\begin{tabular}{cccc}
\hline & $\mathrm{t}$ & $\mathrm{df}$ & $p$ \\
\hline Co-Creative Process & -1.919 & 107 & 0.058
\end{tabular}


than a bad team climate. The results show that team climate plays a very important role in creative collaboration. Indeed, there are significant differences to how teams with a bad team climate work in comparison to those that have a good team climate, thus validating our hypotheses. A good team climate encourages and allows group members to freely and successfully share various ideas during an undertaking. It also permits them to quickly adapt to certain changes during the different phases of an activity. In addition, a team with a good team climate stimulates members to effectively discover and/or create solutions to problems that are new, original, effective and have value.

The results from this study appear to be consistent with previous tests performed on similar subjects. A study by Eteläpelto and Lahti (2008) on the resources and obstacles of creative collaboration in a long-term learning community, found that from the perspective of creativity, emotional and affective aspects are indeed highly significant. This is also in line with prior research on the role of emotional aspects for creative collaboration (Littleton \& Miell, 2004; Moran \& John-Steiner, 2004; Storey \& Joubert, 2004). In a recent study by Stel (2017) on the impact of team composition and team climate on the performance of innovation teams, it was found that a healthy team climate in which all team members feel safe and are eager to participate is essential for team performance. This finding is also supported by another related study by Richardson and Mishra (2018) where they concluded that creativity can thrive when there is a climate of community, care and cooperation. Moreover, an atmosphere in which students communicate freely, accept and discuss new ideas, trust each other and support risk taking is an ideal climate to support creativity (Craft, 2001; Esquivel, 1995; Peterson \& Harrison III, 2005).

In parallel, during our preliminary analyses, where each statement of the questionnaire was examined, we saw a surprising result. Although the majority of participants responded positively by selecting "Strongly agree" or "Somewhat agree" to the items in the three factors, this was not the case for the "Iterative process" under "Co-creative process". This signifies that most groups did not go through the different cycles of calculated trial and error before arriving at the desired end result. Some of the factors that may have influenced this outcome is the type of techno-creative activity chosen in the Makerium.fr platform (Pixel Art) and the way it is presented to the participants during the third session where they took up the challenge collectively. Since each group had been given a model to copy, all they had to do was simply match the correct post-its to that of their reference. They did not feel the need to go through the different stages of the session nor the necessity to actually discover for themselves where and what positions should the post-its be.

Finally, after discovering that the team climate has an influence on the co-creativity and solution orientation process of students, a further analysis was conducted to determine whether imposed or non-imposed groups could have an effect on the three factors of this study: team climate, co-creative process and solution orientation. The results showed insignificant differences in the process 
of co-creativity and solution orientation factors. The team climate factor, on the other hand, was found to be significant suggesting a difference in the level of how a student perceives the interrelationships among the team members between the groups. This outcome is related to the findings of Hilton and Phillips (2010) in their study on how the formation of groups affects the group experience. They discovered that student-selected groups perceived a better overall team climate as members share similarities in several dimensions including backgrounds, interests, project commitment, and determination to succeed as a group. These similarities contributed to feelings of ease, comfort, and trust. The authors also state that student-selected groups reported to have greater participation and work sharing by group members. It is therefore fundamental to take into consideration that the team climate of a group is very important, and that it could also be defined by the manner in which the groups are formed.

\section{Conclusion}

To conclude, our data suggest that for the processes of co-creativity and solution orientation to effectively and efficiently take place in a collaborative activity, the atmosphere must be conducive and emotionally positive. The trust should be evident in the group, and each member should freely express opinions and be open to exploring various ideas to develop a solution to a problem. Also, from a more practical point of view, the application of these results in schools could prove to be a great source of motivation for students. Indeed, a bad team climate seems to have big consequences on the students and could therefore be detrimental to the smooth running of activities. Knowing this could allow teachers to make the necessary adjustments even before starting activities, so as to favor the general climate and thus the students' learning.

\section{Limitations}

The study described in this paper has some limitations that should also be acknowledged. During the implementation phase of this study, it was observed that the simplified version of the questionnaire was still too difficult for the younger participants to understand due to some complicated words, despite having guidance from the teachers and the experimenter present on site. It was also noted that some of them looked at the responses of their seatmates and copied them. Because they had difficulties in analyzing their experiences, some participants may have answered the questionnaire at random.

Additionally, according to some teachers, some participants did not have a clear understanding of the difference in degree of the scale options. For this reason, one teacher even decided to change the scale into smileys. This could have influenced the responses of the participants; they may have chosen responses that don't correspond exactly to their experience during the activity.

Lastly, some teachers observed that the participants worked very well with their classmates during the activity. However, the aforementioned observations 
from the teachers were not reflected on the questionnaires when the participants completed them.

\section{Funding}

This research has been subsidized by the Edu'Up program, set up by the Ministry of Education to support the production of innovative digital solutions adapted to children, and by Trézorium, the company which created the Makerium.fr platform, with aims to develop digital resources (challenges/tutorials) for schools and specifically for teachers in cycles 2 and 3.

\section{Acknowledgements}

The authors would like to thank those who offered advice, contacts, references, and comments, including: the members of the company Trézorium as well as the teachers who agreed to participate in this study within the framework of the Edu'Up project; Romuald Delattre, member of "Objectif Territoire Apprenant" 62 (Pas de Calais regional project); Benoît Becquart, the education inspector; Maud Besançon; and the Digital Educational Innovation Laboratory (LINE) of the Université Côte d'Azur.

\section{Conflicts of Interest}

The authors declare no conflicts of interest regarding the publication of this paper.

\section{References}

Anderson, C. (2012). Makers: The New Industrial Revolution (Edition Unstated éd.). Crown Business.

Bolden, B., DeLuca, C., Kukkonen, T., Roy, S., \& Wearing, J. (2020). Context and Implications Document for: Assessment of Creativity in K-12 Education: A Scoping Review. Review of Education, 8, 377-379. https://doi.org/10.1002/rev3.3187

Brown, R. T. (1989). Creativity. In J. A. Glover, R. R. Ronning, \& C. R. Reynolds (Eds.), Handbook of Creativity (pp. 3-32). Springer. https://doi.org/10.1007/978-1-4757-5356-1_1

Craft, A. (2001). An Analysis of Research and Literature on Creativity in Education. Qualifications and Curriculum Authority, 51, 1-37.

Csikszentmihalyi, M. (1998). Creativity and Genius: A Systems Perspective. In A. Steptoe (Ed.), Genius and the Mind Studies of Creativity and Temperament (pp. 38-65). Oxford University Press. https://doi.org/10.1093/acprof:oso/9780198523734.003.0003

David, D., Romero, M., \& De Smet, C. (Submitted). Développement d'une échelle de co-créativité en contexte d'apprentissage collaboratif en pédagogie universitaire.

Davies, D., Jindal-Snape, D., Collier, C., Digby, R., Hay, P., \& Howe, A. (2013). Creative Learning Environments in Education-A Systematic Literature Review. Thinking Skills and Creativity, 8, 80-91. https://doi.org/10.1016/j.tsc.2012.07.004

Eccles, J. S., \& Roeser, R. W. (2011). Schools as Developmental Contexts during Adolescence. Journal of Research on Adolescence, 21, 225-241.

https://doi.org/10.1111/j.1532-7795.2010.00725.x 
Esquivel, G. B. (1995). Teacher Behaviors That Foster Creativity. Educational Psychology Review, 7, 185-202. https://doi.org/10.1007/BF02212493

Eteläpelto, A., \& Lahti, J. (2008). The Resources and Obstacles of Creative Collaboration in a Long-Term Learning Community. Thinking Skills and Creativity, 3, 226-240. https://doi.org/10.1016/j.tsc.2008.09.003

Ferrari, A., Cachia, R., \& Punie, Y. (2009). Innovation and Creativity in Education and Training in the EU Member States: Fostering Creative Learning and Supporting Innovative Teaching Literature Review on Innovation and Creativity in E\&T in the EU Member States (ICEAC).

Fleming, M. (2010). Arts in Education and Creativity: A Literature Review (2nd ed.). Creativity, Culture and Education.

Guilford, J. P. (1950). Creativity. American Psychologist, 5, 444-454. https://doi.org/10.1037/h0063487

Harper, R., Rodden, T., Rogers, Y., \& Sellen, A. (2008). Being Human: Human Computer Interaction in 2020. Microsoft Research.

Heiser, L., Romero, M., De Smet, C., \& Faller, C. (2020). Conception d'activités technocréatives pour le développement d'une pédagogie créative. Formation et profession, 28, 51-59. https://doi.org/10.18162/fp.2020.547

Hilton, S., \& Phillips, F. (2010). Instructor-Assigned and Student-Selected Groups: A View from Inside. Issues in Accounting Education, 25, 15-33. https://doi.org/10.2308/iace.2010.25.1.15

Jones, K. (2009). Culture and Creative Learning: A Literature Review. Creativity, Culture and Education.

Katz-Buonincontro, J., \& Anderson, R. C. (2018). A Review of Articles Using Observation Methods to Study Creativity in Education (1980-2018). The Journal of Creative Behavior, 54, 508-524. https://doi.org/10.1002/jocb.385

Lambropoulos, N., Romero, M., \& Kommers, P. A. M. (2011). Editorial: Special Issue on Community-Based Innovation: Designing Shared Spaces for Collaborative Creativity. International Journal of Web Based Communities, 7, 403-406.

Littleton, K., \& Miell, D. (2004). Collaborative Creativity: Contemporary Perspectives. In D. Miell, \& K. Littleton (Eds.), Collaborative Creativity: Contemporary Perspectives (pp. 1-8). Free Association Books.

Lubart, T., Mouchiroud, C., Tordjman, S., \& Zenasni, F. (2015). Psychologie de la créativité(2nd ed.). Armand Colin.

Moran, S., \& John-Steiner, V. (2004). How Collaboration in Creative Work Impacts Identity and Motivation. In D. Miell, \& K. Littleton (Eds.), Collaborative Creativity: Contemporary Perspectives (pp. 11-25). Free Association Books.

Oner, A., Nite, S., Capraro, R., \& Capraro, M. (2016). From STEM to STEAM: Students' Beliefs about the Use of Their Creativity. STEAM, 2, 1-14.

https://doi.org/10.5642/steam.20160202.06

Perignat, E., \& Katz-Bounincontro, J. (2019). STEAM in Practice and Research: An Integrative Literature Review. Thinking Skills and Creativity, 31, 31-43. https://doi.org/10.1016/j.tsc.2018.10.002

Peterson, R. E., \& Harrison III, H. L. (2005). The Created Environment: An Assessment tool for Technology Education Teachers: Creativity Doesn't Just Happen by Chance; the Prepared Environment Nourishes It. The Technology Teacher, 64, 7-11.

Puozzo, I. (2016). La créativité en éducation et en formation. Perspectives théoriques et pratiques. Louvain-La-Neuve, Belgique: De Boeck. 
Richardson, C., \& Mishra, P. (2018). Learning Environments That Support Student Creativity: Developing the SCALE. Thinking Skills and Creativity, 27, 45-54.

https://doi.org/10.1016/j.tsc.2017.11.004

Romero, M., \& Barberà, E. (2014). Computer-Based Creative Collaboration in Online Learning. In International Conference on Web-Based Learning (pp. 330-336). Springer. https://doi.org/10.1007/978-3-662-43454-3_34

Romero, M., Lille, B., \& Patiño, A. (2017). Usages créatifs du numérique pour l’apprentissage au XXIe siècle (pp. 1-190). Presses de l’Université du Québec. https://doi.org/10.2307/j.ctt1vw0rkx

Stel, F. (2017). The Impact of Team Composition and Team Climate on the Performance of Innovation Teams. ISPIM 20167, Vienna, 6 November 2017, 1-13.

Sternberg, R. J. (2015). Teaching for Creativity: The Sounds of Silence. Psychology of Aesthetics, Creativity, and the Arts, 9, 115-117. https://doi.org/10.1037/aca0000007

Storey, H., \& Joubert, M. M. (2004). The Emotional Dance of Creative Collaboration. In D. Miell, \& K. Littleton (Eds.), Collaborative Creativity: Contemporary Perspectives (pp. 40-51). Free Association Books.

Timotheou, S., \& Ioannou, A. (2021). Collective Creativity in STEAM Making Activities. The Journal of Educational Research, 114, 1-16. https://doi.org/10.1080/00220671.2021.1873721

van Laar, E., van Deursen, A. J. A. M., van Dijk, J. A. G. M., \& de Haan, J. (2017). The Relation between 21st-Century Skills and Digital Skills: A Systematic Literature Review. Computers in Human Behavior, 72, 577-588. https://doi.org/10.1016/j.chb.2017.03.010

Voogt, J., Laferrière, T., Breuleux, A., Itow, R. C., Hickey, D. T., \& McKenney, S. (2015). Collaborative Design as a Form of Professional Development. Instructional Science, 43, 259-282. https://doi.org/10.1007/s11251-014-9340-7

Wishart, J., \& Eagle, S. (2014). The Development of a Scale to Assess Creative Collaboration via Online Tools. In New Horizons in Web-Based Learning (pp. 320-329). Springer. https://doi.org/10.1007/978-3-662-43454-3_33 